\title{
Análise Crítica do Gênero \\ Reportagem Didática na Revista Nova Escola
}

\author{
Critical Genre Analysis of Didactic Reportage \\ IN THE Magazine Nova Escola
}

Francieli Matzenbacher Pinton*

Resumo: Partindo da concepção de gênero como ação social, tipificada e recorrente (MILLER, 1984; BAZERMAN, 2009), este artigo tem por objetivo analisar criticamente o gênero reportagem didática veiculado na revista Nova Escola entre os anos 2006 e 2010. O corpus é constituído de 15 reportagens destinadas à popularização de conhecimentos sobre o ensino de produção textual na educação básica. As reportagens foram analisadas à luz da Análise de Gênero na perspectiva da Sociorretórica (SWALES, 1990, 1998; BAZERMAN, 2006, 2009) e do Metadiscurso (HYLAND, 2005). Os resultados apontam para quatro movimentos retóricos que visam à didatização de um determinado conteúdo e sua posterior aplicação em sala de aula. As estratégias metadiscursivas utilizadas são: 1) atenuadores; 2) enfatizadores; 3) atitudinais; 4) automenção e 5) marcadores de atenção. Portanto, os operadores utilizados reforçam o propósito da revista e do gênero discursivo que é a orientação diretiva dos conteúdos e das metodologias divulgados para seus leitores.

Palavras-chave: Análise de gênero. Reportagem didática. Revista Nova Escola.

Abstract: This article aims to critically analyze the genre didactic reportage in the magazine Nova Escola between 2006 and 2010. The corpus is composed

\footnotetext{
* Doutorado em Letras pela Universidade Federal de Santa Maria (2012). Professora Adjunto A da UFSM. Contato: japinton@gmail.com.
} 
of 15 pieces of didactic reportage aiming at the popularization of the knowledge on teaching textual production in elementary education. The texts were analyzed under the perspective of Genre Analysis, especially under the socio-rhetorical perspective (SWALES, 1990, 1998; BAZERMAN, 2006, 2009) and Metadiscourse (HYLAND, 2005). The results point to four rhetorical moves aimed at the didactization of a particular content and its subsequent application in the classroom. The metadiscursive strategies used to express the position of the journalist can be summarized as: 1) attenuators; 2) highlighters; 3) attitudinal; 4) self-mention and 5) markers of attention. Therefore, the operators used reinforce the purpose of the magazine and of the discursive genre that is the directive guidance of the contents and methodologies disclosed to its readers.

Keywords: Genre Analysis. Didactic reportage. Magazine Nova Escola.

\section{Introdução}

Entendendo gênero como ação social (MILLER, 1984), tipificada e recorrente (BAZERMAN, 2009) e, portanto, como evento discursivo situado em contextos recorrentes da experiência humana (MOTTA-ROTH, 2008), pode-se afirmar que os gêneros exercem um papel estruturador da cultura, com o poder de encapsular as diferentes formas de identificar e representar os aspectos da vida humana. Assim, os gêneros tipificam não somente a forma textual, mas também o modo como os seres humanos dão forma às atividades sociais (BAZERMAN, 2008). A apropriação de um determinado gênero discursivo permite ao sujeito inserir-se em uma prática social, discursiva e textual e, ao mesmo tempo, conscientizar-se dos processos ideológicos do discurso, tornando "as pessoas mais conscientes de sua própria prática e mais críticas dos discursos investidos ideologicamente a que são submetidas" (FAIRCLOUGH, 2008). Nesse sentido, a investigação de gêneros que popularizam saberes para os professores torna-se relevante, uma vez que possibilita desvelar discursos naturalizados sobre ensino e 
aprendizagem ${ }^{1}$. Em razão disso, este artigo tem por objetivo analisar criticamente o gênero reportagem didática veiculado na revista Nova Escola ${ }^{2}$ entre os anos 2006 e 2010. Para dar conta desse objetivo, organizei o artigo em quatro etapas. Primeiramente, apresento o referencial para análise de gênero na ótica da Sociorretórica, discutindo conceitos-chave como gênero e reportagem. Logo após, descrevo os procedimentos metodológicos adotados para análise do gênero reportagem didática. Na seção subsequente, analiso a organização retórica do gênero, bem como os marcadores metadiscursivos empregados pelo produtor/jornalista. Por fim, apresento as considerações finais em relação a esta pesquisa.

\section{Análise de Gênero na Perspectiva da Sociorretórica}

A Análise de Gênero na perspectiva da Sociorretórica busca explicitar as relações entre o texto e o contexto a fim de explicar os aspectos ideológicos que estão materializados linguisticamente nos diferentes gêneros que circulam na sociedade. Em vista disso, os estudos da Sociorretórica priorizam as noções de propósito e de contexto. Nessa perspectiva, o gênero é entendido como uma ação retórica tipificada que funciona como uma resposta a situações recorrentes e definidas socialmente. Por isso, a compreensão dos gêneros que constituem a vida em sociedade pode contribuir para a explicação de como encontramos, interpretamos, reagimos e criamos certos textos (Cf.: MILLER, 1984, p. 151). Em consonância a isso, Bazerman (2009, p. 22) aponta para a ideia de que cada texto cria para seus leitores um fato social. O conceito de fato social remete a ações significativas realizadas pela linguagem. Assim, esses fatos são realizados por meio de ações retóricas padronizadas,

${ }^{1}$ Esta pesquisa está vinculada Grupo de Pesquisa/CNPq Linguagem como Prática Social e ao Grupo de Trabalho do Laboratório de Leitura e de Redação (LabLeR) da UFSM,

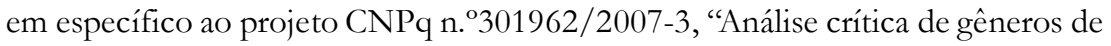
artigo de popularização da ciência", que investiga os diferentes aspectos de popularização da ciência.

${ }^{2}$ Considerada a revista que possui maior circulação mensal entre as revistas mensais pagas, conforme dados Associação Nacional dos Editores de Revistas (ANER). Disponível em: <http://bit.do/bGNXL>. Acesso em: 23 ago. 2010. 
típicas, ou seja, por meio de gêneros, que ocorrem em circunstâncias relacionadas.

Nessa linha, o trabalho de Swales $(1990,1998)$ tem contribuído significativamente ao propor uma etnografia da escrita, em que são considerados os papéis que os textos desempenham em determinados contextos. O foco desta análise textual é a organização retórica, isto é, a explicitação da forma como a organização textual revela aspectos do evento comunicativo ao qual o texto está ligado. Para analisar a organização retórica, as categorias de análise são os movimentos e os passos. De acordo com Swales (2004, p. 228), o movimento é uma unidade discursiva ou retórica que desempenha uma função comunicativa. Cada movimento inclui unidades menores definidas como passos; estes são elementos constitutivos que se combinam para formar a informação que constitui o movimento (MOT'TAROTH, 1995, p. 47).

Um dos exemplos mais conhecidos de análise da organização retórica é o chamado modelo CARS (Create a Research Space), proposto por Swales para descrever a seção de introdução em artigos científicos. O valor do modelo CARS está na ideia de que certos movimentos retóricos aparecem nos textos com objetivo de atingir um determinado efeito de sentido, tendo em vista um propósito comunicativo. Vários pesquisadores já testaram esse modelo de organização de informações proposto por Swales. Em gêneros da esfera midiática, Silva (2002) aplicou o modelo para estabelecer uma distinção entre notícia e reportagem; Bonini (2009) para distinguir diferentes tipos de reportagem; Motta-Roth e Lovato (2009) para elaborar uma representação esquemática da organização retórica de notícias de popularização da ciência em inglês e português.

Como este trabalho foca o texto midiático, em especial aquele publicado na revista Nova Escola, torna-se relevante a discussão proposta por Bonini (2009), em seu trabalho sobre notícia e reportagem. O autor analisou 377 textos coletados do Jornal do Brasil, identificando oito tipos de reportagens e seus respectivos propósitos: 
Quadro 1 - Propósito comunicativo: notícia e reportagem

\begin{tabular}{|c|l|l|}
\hline Goup & \multicolumn{1}{|c|}{ Genre } & \multicolumn{1}{c|}{ Purpose } \\
\hline \multirow{5}{*}{ Factual } & News & Reporting a fact or an event \\
\cline { 2 - 3 } & $\begin{array}{l}\text { Retrospective } \\
\text { reportage }\end{array}$ & Explaining the fact origin \\
\cline { 2 - 3 } & Opinion reportage & $\begin{array}{l}\text { Approaching a fact or subject through } \\
\text { surveyed opinion(s) }\end{array}$ \\
\cline { 2 - 3 } & Profile reportage & $\begin{array}{l}\text { Describing a person or institution } \\
\text { related to a fact, a current theme, } \\
\text { socially prestigious or famous theme }\end{array}$ \\
\cline { 2 - 3 } & Coverage reportage & $\begin{array}{l}\text { Reporting the Day-to-day of an } \\
\text { institution, big a event/feast, or a } \\
\text { lasting fact }\end{array}$ \\
\hline \multirow{5}{*}{ Thematic } & Product reportage & Describing a new product \\
\cline { 2 - 3 } & Research reportage & $\begin{array}{l}\text { Presenting data on the interpretation } \\
\text { of a current problem or to social } \\
\text { behavior tendency }\end{array}$ \\
\cline { 2 - 4 } & Didactic reportage & $\begin{array}{l}\text { Explaining a subject, trouble } \\
\text { situation or service }\end{array}$ \\
\cline { 2 - 3 } & Itinerary reportage & Presenting tour possibilities \\
\hline
\end{tabular}

Fonte: Bonini (2009, p. 206).

Nesta pesquisa, interessa a discussão sobre a reportagem didática que surge a partir de um assunto ou de situações que requerem um determinado comportamento do leitor ou a aprendizagem de um conhecimento específico (BONINI, 2009, p. 203). Para Bonini, a organização retórica da reportagem didática pode ser definida conforme o Quadro 2.

Ao estudar a popularização da ciência no Diário de Santa Maria, Moreira e Motta-Roth (2008) identificaram dois tipos de reportagem de popularização da ciência: a reportagem de pesquisa e a reportagem didática. Em relação à reportagem didática, as autoras apresentam a organização retórica desse gênero no Quadro 3. 
Quadro 2 - Organização retórica da reportagem didática

\begin{tabular}{|c|l|}
\hline Movimentos & \multicolumn{1}{|c|}{ Passos } \\
\hline Título e subtítulo & $\begin{array}{l}\text { 1. Citar os aspectos mais evidentes (opcionalmente como } \\
\text { complementação ou especificação da informação). }\end{array}$ \\
\hline Introdução & 2. Chamar a atenção para o objeto do conhecimento. \\
\hline \multirow{3}{*}{ Corpo do texto } & $\begin{array}{l}\text { 3. Dar uma visão geral do objeto do conhecimento. } \\
\text { 4. Dar uma definição do objeto do conhecimento. } \\
\text { 5. Descrever aspectos do objeto. } \\
\text { 6. Dar exemplos de como aplicar o conhecimento. } \\
\text { 7. Aconselhar ou recomendar. }\end{array}$ \\
\hline
\end{tabular}

Fonte: Bonini (2009, p. 203).

Quadro 3 - Organização de reportagens didáticas da seção Ideias do Diário de Santa Maria

\begin{tabular}{|c|l|}
\hline Movimentos & \multicolumn{1}{c|}{ Passos } \\
\hline \multirow{3}{*}{ Título e subtítulo } & $\begin{array}{l}\text { 1A Salientar o tema da reportagem } \\
\text { 1B Detalhar o tema da reportagem } \\
\text { 1C Citar nomes e credenciais dos atores da reportagem }\end{array}$ \\
\hline \multirow{2}{*}{ Introdução } & $\begin{array}{l}\text { 2A Retomar o tema da reportagem } \\
\text { 2B Contextualizar o tema da reportagem }\end{array}$ \\
\hline \multirow{2}{*}{ Desenvolvimento } & $\begin{array}{l}\text { 3A Apresentar definição(ões) relacionadas ao tema } \\
\text { 3B Descrever aspectos relacionados ao tema }\end{array}$ \\
& 3C Apresentar exemplos \\
\hline \multirow{2}{*}{ Conclusão } & 4A Aconselhar ou recomendar \\
& 4B Apresentar sugestões \\
\hline Referências & 5A Relacionar fontes de pesquisa \\
\hline
\end{tabular}

Fonte: Moreira e Motta-Roth (2008, p. 8).

Tal representação será considerada neste trabalho como ponto de referência para a análise da reportagem didática. Além disso, considero importante ainda revisar os marcadores metadiscursivos empregados pelos jornalistas que escrevem a reportagem, pois estes podem fornecer uma ligação entre texto e contexto, revelando crenças e valores por parte dos membros que produzem a reportagem. 
O termo metadiscurso pode ser definido como os recursos que os escritores utilizam para organizar explicitamente seus textos, atraindo seus leitores e indicando sua atitude com relação ao material e a seu público (Cf. HYLAND, 2000, p. 104). De acordo com Hyland (2005, p. 3), o metadiscurso incorpora a ideia de que a comunicação é mais do que uma troca de informação, bens e serviços. Ela envolve também personalidade, atitude e hipóteses daqueles que estão comunicando. Dessa forma, pode-se entender o metadiscurso como um meio de articular e de produzir essas interações, ou seja, a forma como se negocia com os outros e se decide sobre os tipos de efeitos a serem causados nos interlocutores (HYLAND, 2005, p. 13).

Partindo, então, de uma visão da escrita como interação, examinam-se as características discursivas em termos de como os escritores projetam suas experiências, percepções e interesses baseados em uma audiência potencial. O grau de formalidade escolhido pelo escritor, o poder, a compreensão da formação discursiva, da cultura, do conhecimento, da comunidade, todos esses aspectos podem ser marcados metadiscursivamente. Em razão disso, o metadiscurso pode revelar uma importante ligação entre o texto e o contexto, já que aponta para as expectativas que os leitores têm em relação a certas formas de interação e engajamento. A compreensão dos escritores em relação a uma audiência específica, para a qual ele ou ela se direciona, proporciona o caráter altamente dialógico do metadiscurso. As expectativas existentes nessa interação são sociais, afetivas e cognitivas, baseadas nos participantes - suas crenças e seus valores, suas metas individuais e suas experiências com textos similares no passado.

Hyland (2005, p. 49) propõe uma representação para as análises metadiscursivas, afirmando que todo metadiscurso é interpessoal e compreende duas dimensões: a interativa e a interacional. Nesta representação, priorizam-se as finalidades interpessoais e consideram-se as marcas de metadiscurso textual como expedientes usados pelo escritor para incrementar suas estratégias interacionais e avaliativas. Neste trabalho será enfocado o metadiscurso interacional, o qual introduz comentários e avaliações, explicitando seu ponto de vista para o leitor, ou seja, seu posicionamento avaliativo. 
Quadro 4 - Categorias do metadiscurso interacional

\begin{tabular}{|c|l|l|}
\hline $\begin{array}{c}\text { Operadores } \\
\text { metadiscursivos }\end{array}$ & \multicolumn{1}{|c|}{ Função } & \multicolumn{1}{|c|}{ Exemplo } \\
\hline Atenuadores & $\begin{array}{l}\text { Evitam o compromisso do } \\
\text { escritor. }\end{array}$ & $\begin{array}{l}\text { Poderia, talvez, é } \\
\text { possível. }\end{array}$ \\
\hline Enfatizadores & Enfatizam a certeza do escritor. & $\begin{array}{l}\text { De fato, } \\
\text { definitivamente, está } \\
\text { claro, é claro. }\end{array}$ \\
\hline Atitudinais & $\begin{array}{l}\text { Expressam o posicionamento } \\
\text { afetivo do autor em relação ao } \\
\text { conteúdo. }\end{array}$ & $\begin{array}{l}\text { Ainda bem, jeito mais } \\
\text { eficaz. }\end{array}$ \\
\hline Automenção & $\begin{array}{l}\text { Servem para fazer referência ao } \\
\text { autor. }\end{array}$ & Eu, nós, meu, nosso. \\
\hline $\begin{array}{c}\text { Marcadores de } \\
\text { atenção }\end{array}$ & $\begin{array}{l}\text { Buscam dirigir o leitor para o } \\
\text { foco de atenção do escritor, } \\
\text { incluindo afetivamente o leitor } \\
\text { no discurso. }\end{array}$ & $\begin{array}{l}\text { Considere, note, você } \\
\text { pode ver que. }\end{array}$ \\
\hline
\end{tabular}

Fonte: adaptado de Hyland (2005, p. 52-53).

Nesta seção, apresentei a base teórica na qual ancoro minha análise de gênero. Na seção subsequente, apresento os procedimentos metodológicos adotados nesta pesquisa.

\section{Procedimentos Metodológicos}

Como universo de análise, selecionei a revista Nova Escola em virtude de sua recorrente presença em escolas de educação básica. Durante o período de trinta dias, investiguei o site da revista, buscando as edições disponíveis, ou seja, as edições publicadas entre os anos 2006 e 2010. Para isso, recorri aos índices das edições, tendo como critério preliminar textos que em seu título faziam referência à produção de textos ou palavras que remetessem a tal atividade em sala de aula. Como procedimento subsequente, busquei refinar o processo de coleta, incluindo os critérios sugeridos em Motta-Roth (2006): período de tempo, público-alvo e conteúdo dos textos. 
Em relação ao critério período de tempo, foram selecionadas as edições publicadas entre os anos de 2006 e 2010, fator este motivado pela disponibilidade destas edições em versão on-line. Estabelecido o período temporal, decidi que seriam coletados somente os textos destinados aos professores de ensino fundamental, com referência à série ou ao ano feita no título ou no corpo do texto. Isso ocorreu porque circulam textos não só destinados aos professores de ensino fundamental, mas também aos professores de educação infantil. Por fim, selecionei os textos cujo conteúdo reportava o ensino de produção textual - modalidade escrita. Foram coletados 15 textos da versão impressa da revista Nova Escola, conforme o Quadro 5.

Quadro 5 - Numeração, edição e título dos textos do corpus

\begin{tabular}{|l|l|}
\hline $1 \# 198$ & A arte de escrever bem. Nova Escola, ed. 198, p. 42-45, 2006. \\
\hline $2 \# 212$ & Contos 2.0. Nova Escola, ed. 212, p. 54-57, 2008. \\
\hline $3 \# 219$ & Escrever de verdade. Nova Escola, ed. 219, p. 39-45, 2009. \\
\hline $4 \# 220$ & O que cada um sabe. Nova Escola, ed. 220, p. 52-54, 2009. \\
\hline $5 \# 221$ & Ler para escrever. Nova Escola, ed. 221, p. 54-56, 2009. \\
\hline $6 \# 222$ & O que e para quem. Nova Escola, ed. 222, p. 78-80, 2009. \\
\hline $7 \# 223$ & Além da reescrita. Nova Escola, ed. 223, p. 76-78, 2009. \\
\hline $8 \# 224$ & Gêneros, como usar. Nova Escola, ed. 224, p. 48-56, 2009. \\
\hline 9\#225 & Raio X na notícia. Nova Escola, ed. 225, p. 82-84, 2009. \\
\hline $10 \# 226$ & Hora de aperfeiçoar. Nova Escola, ed. 226, p. 90-92, 2009. \\
\hline $11 \# 227$ & De olho na tela. Nova Escola, ed. 227, p. 70-72, 2009. \\
\hline $12 \# 228$ & Lição de mestre. Nova Escola, ed. 228, p. 61-63, 2009. \\
\hline $13 \# 230$ & Autor em formação. Nova Escola, ed. 230, p. 66-68, 2010. \\
\hline $14 \# 231$ & $\begin{array}{l}\text { Como trabalhar a escrita de contos de terror com os alunos. Nova } \\
\text { Escola, ed. 231, p. 45-48, 2010. }\end{array}$ \\
\hline $15 \# 232$ & Sumo do resumo. Nova Escola, ed. 232, p. 82-84, 2010. \\
\hline
\end{tabular}

Fonte: A própria autora. 


\section{Procedimentos de análise contextual e textual-discursiva}

Primeiramente, realizei uma análise documental do site da revista em busca dos objetivos e da missão da revista Nova Escola. Além disso, consultei os sites da Editora Abril e da Associação Nacional de Editores de Revista, com a finalidade de encontrar dados referentes à produção, à circulação e à distribuição da revista. Logo após, elaborei um questionário que foi enviado aos jornalistas da revista com o intuito de tomar conhecimento sobre o contexto de produção do gênero reportagem. Apesar de a revista contar com vários jornalistas, obtive a resposta de apenas um deles.

Na sequência, realizei a análise da organização retórica das reportagens com base na representação esquemática proposta por Moreira e MottaRoth (2008), conforme revisão da literatura. Essa análise foi realizada em três etapas: descrição da organização retórica das reportagens didáticas, marcação dos movimentos e passos e tabulação da frequência dos movimentos e passos.

No quarto procedimento, procurei demarcar os operadores metadiscursivos empregados pelo jornalista na reportagem. Para isso, tomei por base o modelo proposto por Hyland (2005), previsto para o metadiscurso interacional. Demarcados os operadores, elaborei uma tabela representativa, a fim de verificar a recorrência de cada um deles nas reportagens e sua relação com a descrição do gênero anteriormente realizada.

\section{A Revista Nova Escola}

A revista começou a circular em março de 1986, período que se tornou conhecido como 'década perdida', em referência aos problemas econômicos no Brasil. Em contrapartida, nesse mesmo período, inúmeras reformas educacionais foram colocadas em prática e, como consequência, houve um aumento dos recursos destinados à educação (SILVA; FEITOSA, 2008). Dessa forma, o nascimento da Nova Escola pode ser entendido como a necessidade de um período histórico, bem como o desejo de contribuir para a formação do professor brasileiro.

Atualmente, a produção da revista impressa é realizada por um grupo de profissionais composto por jornalistas e especialistas em Educação. De 
acordo com as informações fornecidas pelo repórter participante da pesquisa, as pautas da revista são definidas com toda a equipe de trabalho, sendo que cada um dos participantes defende o tema que julgar importante para a reportagem que será produzida. Entretanto, os temas, segundo ele, não surgem apenas do desejo da equipe, mas são também oriundos do contato com as escolas que são citadas na revista e da participação do grupo de jornalistas em congressos e simpósios. Além disso, o repórter revela a preocupação da equipe em contemplar nas reportagens as diferentes áreas do conhecimento e os diferentes níveis de ensino. Informa ainda que o papel da equipe é "encaixar" suas ideias dentro do formato estabelecido pelas disciplinas e pelo nível de ensino, observando, ainda, a importância de abordar determinado assunto em épocas específicas, como, por exemplo, o início das aulas.

Como síntese dos critérios que definem os temas a serem abordados pela revista, tem-se: i) a importância do tema para a educação brasileira naquele momento, critérios de variedade de conteúdos, disciplinas e segmentos, intervalo de tempo em que não foi abordado o assunto, ineditismo (projetos e trabalhos inovadores) e novidades didáticas (o que as pesquisas na área têm apontado como eficiente no processo de ensino e aprendizagem); e ii) os trabalhos enviados por professores para o Prêmio Victor Civita Educador Nota 10.

Quanto aos trabalhos enviados pelos professores Nota 10, o repórter afirma que eles revelam para a equipe pedagógica um panorama da educação brasileira, já que representam os melhores trabalhos realizados pelos professores naquele contexto. Apesar disso, ressalta que muitas dessas práticas de sala de aula apresentam problemas didáticos e é justamente desses trabalhos com problemas que surgem alguns dos temas abordados pela revista.

Em relação à circulação, como evidência do objetivo proposto pela revista, que é o de contribuir para a formação do professor, observa-se o elevado número de exemplares que circulam em todo o Brasil - 738.900³. Destes, 342.922 exemplares são correspondentes a assinaturas, 33.685 correspondentes a vendas avulsas e o restante destinado à distribuição gratuita

${ }^{3}$ Disponível em: <http://bit.do/bGNXR>. Acesso em: 18 ago. 2010. 
para Secretarias de Educação, Fundo Nacional de Desenvolvimento da Educação (FNDE) e outras instituições.

Conforme o diretor de redação da revista, Gabriel Grossi, a revista apontou, em 2008, uma tiragem de um milhão de exemplares circulando em todo o Brasil. Outro dado importante é que os estados de São Paulo, Rio de Janeiro e Tocantins mantêm assinaturas para todos os seus docentes, e o Ministério da Educação adquire mensalmente um lote para ser distribuído nas escolas públicas com mais de 50 alunos matriculados. Além disso, a revista encontra-se à disposição para a compra em locais públicos, como bancas e supermercados, por um preço acessível. Tais dados sinalizam o grande alcance e a popularização da revista entre seu público leitor, essencialmente os profissionais da educação.

Sobre o perfil do leitor da revista, pesquisa realizada pelo Ibope e divulgada pelo Relatório Anual da Fundação Victor Civita aponta que 96\% dos professores afirmam conhecer a revista Nova Escola; $65 \%$ desses professores se consideram leitores regulares; 89\% reforçam o seu caráter utilitário; 88\% julgam pertinentes as informações fornecidas pela revista à prática pedagógica e $87 \%$ acreditam que ela ajuda no cotidiano escolar. Tais dados estão em consonância como o projeto editorial da revista que visa à "apresentação de um vasto conteúdo e a uma maior leveza na diagramação a fim de conquistar seu leitor”. Além disso, nesse mesmo relatório são lançadas as questões que norteiam a redação da revista: i) qual a utilidade dos conteúdos para os professores em suas atividades?, e ii) qual a relevância do tema apresentado na prática pedagógica do professor? Portanto, a análise do contexto de produção permite entender de que forma o processo de comodificação ${ }^{4}$ proposto por Fairclough (2008) se efetiva na revista, garantindo a disseminação das ideias e conteúdos divulgados.

A seguir, apresento o gênero reportagem didática, veiculado nessa revista.

\footnotetext{
${ }^{4}$ A comodificação é o processo pelo qual os domínios e as instituições sociais, cujo propósito não seja produzir mercadorias no sentido econômico restrito de artigos de venda, vêm não obstante a serem organizados e definidos em termos de produção, distribuição e consumo de mercadorias (FAIRCLOUGH, 2008, p. 255).
} 


\section{A organização gráfica do gênero reportagem didática}

A seção "Sala de aula", inscrita na revista Nova Escola, tem por objetivo apresentar ao leitor as relações que contribuem para o aprimoramento do trabalho do professor, de acordo com a informação veiculada no site oficial da revista. Os temas privilegiam aspectos relacionados ao educador/aluno e ao ensino/aprendizagem e simulam o ambiente escolar, estabelecendo uma dinâmica em que os conteúdos das reportagens são referentes às diferentes áreas disciplinares.

Em razão dessa proposta, a produção das reportagens é supervisionada pela coordenadora pedagógica da revista, que orienta a respeito dos conteúdos a serem divulgados para os professores e também sobre a forma assumida pela reportagem neste contexto específico. Segundo o repórter entrevistado, a dinâmica desse gênero pode ser assim descrita:

Antes de começarmos a apuração, o repórter, o editor, a redatorachefe e a coordenadora pedagógica nos reunimos para conversar sobre qual 'pegada' devemos dar ao texto e o que é mais importante de ser abordado. A coordenação sugere artigos e livros que ajudem a reportagem e indica ainda possíveis fontes e caminhos para a apuração. Em geral, consultamos ainda um especialista na área, que irá agir como um consultor, não necessariamente sendo citado.

Sobre o gênero inscrito nessa seção, o repórter afirma que as reportagens produzidas pela revista são diferentes daquelas produzidas pela grande imprensa, pois o foco dessa revista pedagógica é auxiliar o professor a entender conceitos, concepções com vistas ao aperfeiçoamento da prática em sala de aula.

Nessa seção, nos aproximamos mais da divulgação científica (que visa explicar, com uma linguagem acessível, as pesquisas na área de didáticas específicas) do que do jornalismo noticioso. Porém, muitos dos textos tratam de experiências reais, desenvolvidas em sala de aula por professores de todo o Brasil, e, nesse caso, o gênero reportagem fica mais evidente. Em todo o caso, as características 
do texto jornalístico estão todas lá: título e olho com informações precisas, a estrutura básica (abre com as informações principais que serão abordadas, desenvolvimento do texto em núcleos temáticos, discurso indireto para os entrevistados, fotos com legendas etc.), a variedade de fontes (entrevistamos diversos especialistas e colocamos suas opiniões de maneira clara e identificadas), além do viés discursivonarrativo das reportagens (não escrevemos artigos opinativos, mas sim construímos textos baseados no que descobrimos sobre o assunto). Essas reportagens são sempre acompanhadas de Planos de Aula elaborados por especialistas. Publicados num box, eles apresentam um formato próximo ao do planejamento docente. (grifos meus)

As afirmações do jornalista revelam certa dificuldade para definir o gênero inscrito nessa seção de forma precisa. Talvez, tal dificuldade provenha das transformações que o próprio gênero sofreu na revista.

Entre os anos de 2006 e 2007, o gênero estava mais próximo de um relato de experiência, pois essas reportagens contemplavam basicamente as experiências de professoras na educação básica. Nessa perspectiva, a voz do professor, no relato de sua experiência, era justificada e/ou reforçada pela voz do jornalista e dos especialistas, que avaliavam sua prática. Entre 2008 e 2010, o foco passou a ser a divulgação de conteúdos e práticas pedagógicas consideradas "inovadoras" pela revista. Nessa linha, a voz do jornalista passa a ser justificada pela voz do professor, que expõe uma situação prática por ele vivenciada, e pela voz do especialista, que valida cientificamente a teoria e a prática popularizada na revista.

Nesse novo contexto de produção, a voz do professor surge como a de alguém que dá credibilidade prática ao assunto que está sendo abordado, diferentemente do papel exercido pela voz do professor nas reportagens anteriores. Essa prática sinaliza uma inversão: antes; o professor relatava, e o jornalista explicava ou justificava a prática docente; agora, o jornalista populariza um conhecimento produzido pelo cientista que é justificado em uma determinada prática de sala de aula pela voz do professor.

Outro aspecto interessante é que as reportagens publicadas entre 2008 e 2009 estão vinculadas à seção "Sala de aula", seção que surge justamente nesse período. Nesse sentido, parece que a ideia, já sugerida pela modificação 
ocorrida nas capas correspondentes a este período, também acontece nas reportagens que assumem uma linguagem mais dinâmica e próxima das revistas comerciais, como no Exemplo 1:

\section{Exemplo 1}

Seus alunos acham que escrever é chatice? Sofrem para rabiscar uma ou duas linhas e desistem? Não dizem nada com nada? Misturam gêneros - ou, pior, ficam sempre no mesmo, ou, pior ainda, não têm a menor noção do que se trata? Para resolver isso, um caminho é refletir sobre sua prática em sala. Mais especificadamente sobre suas propostas de produção de textos. É bem provável que esteja nelas a raiz da maior parte de suas queixas. (NOVA ESCOLA, 2009, ed. 222, p. 48)

As perguntas retóricas iniciais têm a finalidade de manter uma aproximação com o leitor, demonstrando que o jornalista conhece a realidade escolar, já que faz uma "previsão" dos principais problemas enfrentados pelo docente na escola. Professor e aluno são agentes; entretanto, são as práticas do professor que precisam ser revistas e, para isso, a reportagem "promete" dar o caminho. Tal estratégia discursiva aproxima-se muito do discurso publicitário, pois aponta um problema e oferece um "produto" como solução.

Nas reportagens, primeiramente, é apresentada a seção e a área ou o assunto que será abordado. Logo após, são apresentados o título e o subtítulo da reportagem, o nome do jornalista e o seu endereço eletrônico. Além disso, em algumas reportagens há uma seta indicando se o tópico apresentado foi sugerido pelos leitores e/ou se é uma reportagem de uma determinada série produzida pela revista. Essa estratégia contribui para a representação de que o leitor tem o poder de interferir nas escolhas dos temas da reportagem, revelando o diálogo entre os que produzem e os que consomem a revista.

No corpo do texto da reportagem são inseridas imagens e vários boxes. Apesar de os boxes sempre existirem, são recorrentes apenas dois nas seções "Sala de aula" e "Capa": a "Sequência didática" (existe a variável para a sequência didática que é o projeto didático) e o "Quer saber mais". 
No boxe "Sequência didática", a equipe ou um consultor da revista apresenta um plano de aula sobre o conteúdo que foi popularizado. A organização da sequência apresenta os objetivos, os conteúdos, a série/ano para a/o qual a aula é indicada (normalmente são contemplados dois anos, por exemplo, sétimo e oitavo anos), o material necessário, o desenvolvimento das atividades propostas e, por fim, a avaliação do conteúdo ministrado.

Os projetos didáticos e as sequências didáticas diferem em relação ao tempo previsto para execução, por exemplo, quando se trata das sequências, o tempo é calculado em horas-aula; nos projetos didáticos, em meses, normalmente o período equivalente a um mês. Os passos a serem seguidos são idênticos aos da sequência didática. Dessa forma, as sequências e os projetos se configuram mais como uma ampliação dos planos de aula já propostos pela revista em anos anteriores a 2009. Apesar de ser popularizada pela revista a proposta da Pedagogia de Gêneros da Escola Suíça, as sequências didáticas apresentadas pela Nova Escola encontram-se bastante distantes do conceito proposto pela Didática de Línguas genebrina e expandido pelo grupo de pesquisadores brasileiros, "uma vez que, em muitas situações, as sequências não contemplam as características sociodiscursivas do gênero textual que deve ser produzido pelo aluno" (ANJOS-SANTOS; LANFERDINI; CRISTOVÃO, 2011, p. 396).

No boxe "Quer saber mais?", o leitor encontra algumas referências bibliográficas e o endereço eletrônico de especialistas na área. O objetivo desse boxe é que os professores aprofundem os conhecimentos popularizados nas reportagens que leram. Conforme o repórter, as fontes teóricas normalmente são artigos e livros publicados por especialistas. O repórter acrescenta que, nas reportagens didáticas, "há muito mais dessas fontes do que a fala que colocamos entre aspas".

Portanto, a seção "Sala de aula" pode ser considerada como o espaço reservado à popularização das teorias e metodologias de ensino das diferentes disciplinas que compõem o currículo escolar. Já o gênero reportagem didática pode ser compreendido como a materialização dos propósitos dessa seção. $\mathrm{Na}$ sequência, descreverei a organização retórica do gênero reportagem didática. 
Nesta subseção, o objetivo é analisar o gênero discursivo considerado neste trabalho como o responsável pela popularização dos conhecimentos teóricos e metodológicos para o leitor professor. Apresento, a seguir, a organização retórica do gênero na revista, partindo da representação proposta por Moreira e Motta-Roth (2008).

Quadro 6 - Movimentos e passos da reportagem didática na revista Nova Escola

\begin{tabular}{|c|l|}
\hline Movimentos & \multicolumn{1}{|c|}{ Passos } \\
\hline $\begin{array}{c}\text { M1 Apresentar o } \\
\text { tema }\end{array}$ & $\begin{array}{l}\text { 1A Salientar o tema da reportagem e } \\
\text { 1B Explicitar o tema da reportagem e } \\
\text { 1C Identificar o nome e o endereço eletrônico do } \\
\text { jornalista }\end{array}$ \\
\hline $\begin{array}{c}\text { M2 Situar o } \\
\text { tema }\end{array}$ & $\begin{array}{l}\text { 2A Contextualizar o tema da reportagem e } \\
\text { 2B Detalhar o tema da reportagem }\end{array}$ \\
\hline $\begin{array}{c}\text { M3 Didatizar o } \\
\text { tema }\end{array}$ & $\begin{array}{l}\text { 3A Apresentar definição(ões) relacionadas ao tema e } \\
\text { 3B Descrever aspectos relacionados ao tema } \\
\text { 3C Apresentar uma atividade e/ou dar exemplos } \\
\text { 3D Relatar a atividade prática e } \\
\text { 3E Avaliar a atividade prática }\end{array}$ \\
\hline $\begin{array}{c}\text { M4 Avaliar } \\
\text { positivamente o } \\
\text { tema }\end{array}$ & $\begin{array}{l}\text { 4A Reforçar a importância da aplicabilidade do tema e } \\
\text { da prática em sala aula }\end{array}$ \\
\hline
\end{tabular}

Fonte: A própria autora.

O Movimento 1 (Apresentar o tema) chama a atenção para o conteúdo que será apresentado, enfatizando os aspectos que serão didatizados na reportagem. Uma característica singular é que o tema surge primeiramente de forma ampla no título para, posteriormente, ser explicitado no subtítulo. Os Exemplos 2 e 3 ilustram tal movimento, com destaque dos lexemas explícitos observados:

${ }^{5}$ Os passos em negrito sinalizam as diferenças entre as reportagens didáticas da Nova Escola e as reportagens didáticas do Diário de Santa Maria. 
Exemplo 2

O que cada um sabe

Analisar detalhadamente a forma como os alunos escrevem é a primeira providência para determinar os pontos que devem ser ensinados. (NOVA ESCOLA, 2009, ed. 220, p. 52)

Exemplo 3

Escrever de verdade

Para produzir textos de qualidade, seus alunos têm de saber o que querem dizer, para quem escrevem e qual é o gênero que melhor exprime essas ideias. A chave é ler muito e revisar continuamente. (NOVA ESCOLA, 2009, ed. 219, p. 39)

O Movimento 2 (Situar o tema) contextualiza o tema (Passo 2A) que será abordado, detalhando (Passo $2 \mathrm{~B}$ ) as práticas consideradas inovadoras pela revista.

Exemplo 4

MOVIMENTO 1

Sem medo de escrever

Histórias de terror entram em sala de aula e dão aos alunos a possibilidade de trabalhar com esse gênero, cheio de mistério e suspense.

\section{MOVIMENTO 2}

Não leia esta reportagem se você evita as histórias de terror. Pare imediatamente, pois ela pode causar arrepios. Se prosseguir, por seu próprio risco, é porque sabe que o suspense e o medo típicos desse gênero (histórias de terror) são cativantes. (NOVA ESCOLA, 2010, ed. 231, p. 75)

O Movimento 3 (Didatizar o tema) didatiza o tema para o leitor, apresentando a teoria e os passos que devem ser seguidos e/ou apresentando e descrevendo uma atividade prática. No passo 3A (definições relacionadas ao tema), são apresentados os conceitos que posteriormente serão retomados nas sugestões de atividades de produção textual, como neste Exemplo 5. 


\section{Exemplo 5}

Produzir textos é um processo que envolve diferentes etapas: planejar, escrever, revisar e re-escrever. Esses comportamentos escritores são os conteúdos fundamentais da produção escrita. A revisão não consiste em corrigir apenas erros ortográficos e gramaticais, como se fazia antes, mas cuidar para que o texto cumpra sua finalidade comunicativa. "Deve-se olhar para a produção dos estudantes e identificar o que provoca estranhamento no leitor dentro dos usos sociais que ela terá", explica Fernanda Liberali. (NOVA ESCOLA, 2009 , ed. 219, p. 40)

No passo subsequente, 3B, são descritos os aspectos relativos ao tema abordado (Exemplo 6).

\section{Exemplo 6}

Um escritor proficiente, no entanto, não faz a revisão só no fim do trabalho. Durante a escrita, é comum reler o trecho já produzido e verificar se ele está adequado aos objetivos e às ideias que tinha intenção de comunicar - só então planeja-se a continuação. E isso é feito por todo escritor profissional. A revisão em processo e a final são passos fundamentais para conseguir de fato uma boa escrita. (NOVA ESCOLA, 2009, ed. 219, p. 40)

Já no passo 3C, a atividade é didatizada, explicitando-se para o professor a forma pela qual esta deverá ser realizada em sala de aula (Exemplo 7).

\section{Exemplo 7}

Antes de começar a atividade, é preciso montar uma lista com os itens que serão analisados. Não podem faltar aspectos relacionados aos padrões de escrita e às características do texto. Do 3 ano ao 5 ano, o foco deve recair sobre a ortografia e a pontuação e é essencial verificar se a turma conhece e respeita os traços do gênero escolhido. Em seguida, você já pode pedir que os alunos escrevam. (NOVA ESCOLA, 2009, ed. 220, p. 52) 
No passo seguinte, 3C, uma atividade prática é descrita, explicitando as etapas que foram desenvolvidas pelo professor nas aulas, conforme Exemplo 8.

\section{Exemplo 8}

Procurando desenvolver a leitura crítica de textos jornalísticos e o conhecimento das estruturas argumentativas na produção textual, ela propôs uma atividade permanente: a cada semana, um grupo elegia uma notícia e expunha à turma a forma como ela tinha sido tratada nos jornais. [...] Paralelamente, os estudantes tiveram contato com textos de finalidades comunicativas diversas no jornal, como cartas de leitores, editoriais, artigos opinativos e horóscopo. "O objetivo era que eles analisassem os materiais, refletissem sobre os propósitos de cada um e adquirissem um repertório discursivo e linguístico", conta Maria Teresa, que lançou um desafio: produzir um jornal mural. A proposta era trabalhar com textos opinativos, como os editoriais. Para que a escrita ganhasse sentido, ela avisou que o jornal seria afixado no corredor e que toda a comunidade escolar teria acesso a ele. A primeira versão foi lida pela professora. [...] Divididos em pequenos grupos, os alunos revisaram a produção de um colega, escrevendo um bilhete para o autor com sugestões e avaliando se ela estava adequada para publicação. [...] (NOVA ESCOLA, 2009, ed. 219, p. 48)

Como passo final, em 3D, a atividade é avaliada por um especialista, pelo jornalista ou, ainda, pelo próprio professor, de acordo com o Exemplo 9.

\section{Exemplo 9}

A pesquisadora argentina em didática Mirta Castedo é defensora desse tipo de proposta. Para ela, as situações de revisão em grupo desenvolvem a reflexão sobre o que foi produzido por meio justamente da troca de opiniões e críticas. "Revisar o que os colegas fazem é interessante, pois o aluno se coloca no lugar de leitor", emenda Telma. "Quando volta para a própria produção e faz a 
revisão, a criança tem mais condições de criar distanciamento dela e enxergar fragilidades." (NOVA ESCOLA, 2009, ed. 219, p. 49)

O Movimento 4 (Avaliar positivamente o tema) - reforça a importância da aplicabilidade do tema e da prática apresentada no cotidiano da sala de aula, conforme o Exemplo 10.

\section{Exemplo 10}

Por fim, vale destacar que quando os gêneros são ensinados como instrumento para a compreensão da língua, não importa quantos ou quais você trabalha, desde que o objetivo seja usá-los como um jeito de formar alunos que aprendam a ler e a escrever de verdade. (NOVA ESCOLA, 2009, ed. 224, p. 56)

Os passos que constituem os movimentos nem sempre ocorrem de forma linear, ou seja, um após o outro. Além disso, em algumas das reportagens, constatei que alguns passos são suprimidos. A falta de constância de alguns passos sugere a fluidez do gênero reportagem didática na revista, marcado pelos estilos de cada um dos jornalistas. De forma específica, percebe-se que, nos textos 1 e 2, os passos 3A (apresentar definição relacionadas ao tema), 3B (descrever aspectos relacionados ao tema) e 3C (apresentar uma atividade e/ou dar exemplos) não ocorrem, o que se justifica em função de que as primeiras reportagens apresentavam uma organização muito próxima de relatos de experiências bem-sucedidas em sala de aula. Outro aspecto importante é que, nos textos 5, 6 e 7, o passo 3D (relatar uma atividade prática) é suprimido, sendo apresentados somente exemplos práticos ao leitor.

Nessa perspectiva, parece que a reportagem didática da Nova Escola cumpre o papel de subsidiar o professor-leitor, divulgando para ele a teoria e sua posterior didatização. Assim, reserva-se ao professor o papel de executor da aula planejada por especialistas da área. Entendo que o gênero descrito, de certa forma, encapsula o propósito da revista identificado em seu contexto de produção e circulação, bem como em seu projeto textual e discursivo. 
A indicação do posicionamento e a avaliação do jornalista é explicitada pelos marcadores metadiscursivos interacionais. São eles que evidenciam o posicionamento do autor em relação à informação textual, marcando o diálogo entre os participantes da interação e anunciando a presença explícita do autor no texto. Nas reportagens didáticas analisadas, há a presença recorrente dos quatro marcadores já identificados por Hyland (2005): os atenuadores, os enfatizadores, os atitudinais e os marcadores de atenção. A recorrência desses marcadores pode ser visualizada na Tabela 1.

Tabela 1 - Percentual de ocorrência dos operadores metadiscursivos interacionais

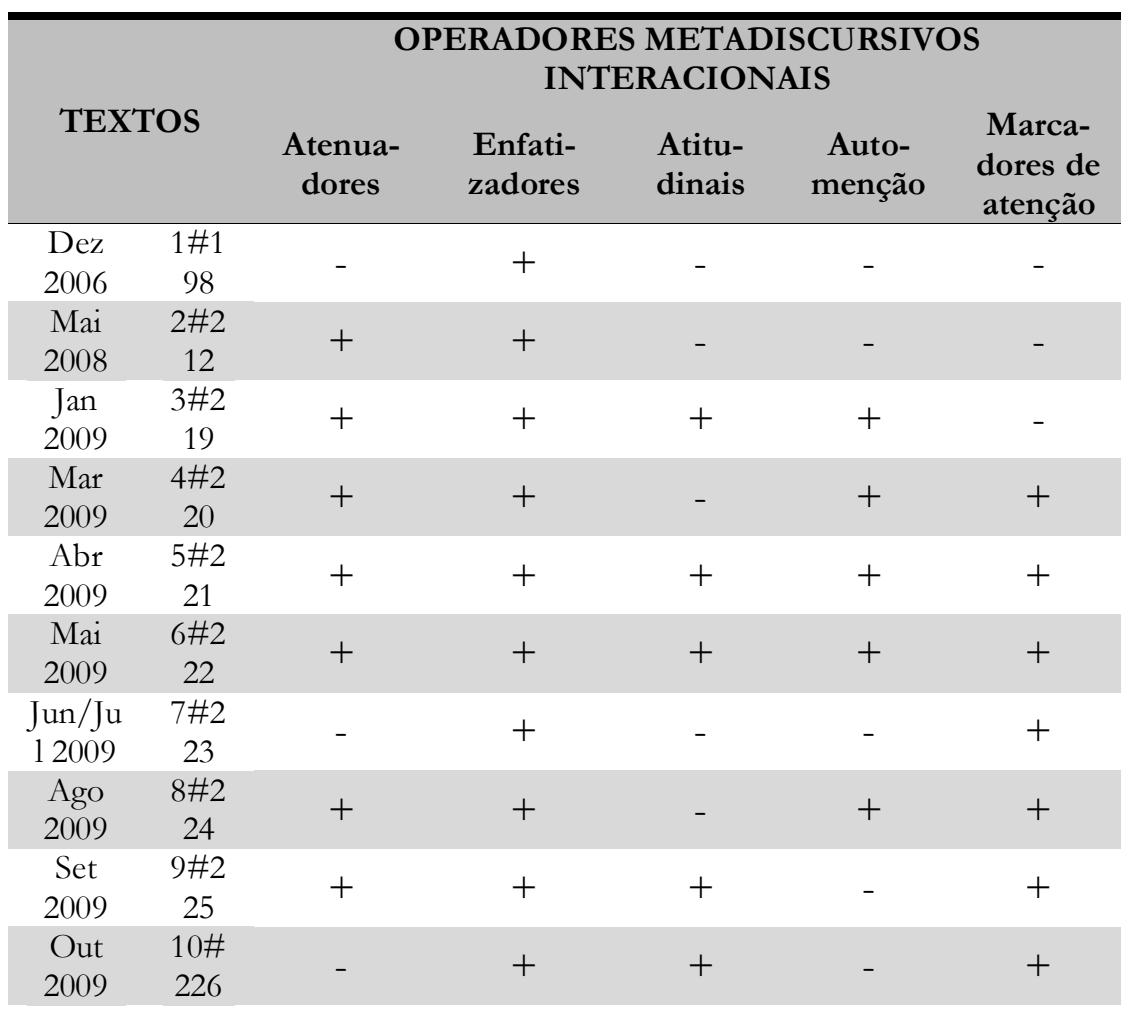




\begin{tabular}{|c|c|c|c|c|c|c|}
\hline \multirow{2}{*}{\multicolumn{2}{|c|}{ TEXTOS }} & \multicolumn{5}{|c|}{$\begin{array}{c}\text { OPERADORES METADISCURSIVOS } \\
\text { INTERACIONAIS }\end{array}$} \\
\hline & & $\begin{array}{l}\text { Atenua- } \\
\text { dores }\end{array}$ & $\begin{array}{l}\text { Enfati- } \\
\text { zadores }\end{array}$ & $\begin{array}{l}\text { Atitu- } \\
\text { dinais }\end{array}$ & $\begin{array}{l}\text { Auto- } \\
\text { menção }\end{array}$ & $\begin{array}{l}\text { Marca- } \\
\text { dores de } \\
\text { atenção }\end{array}$ \\
\hline $\begin{array}{l}\text { Nov } \\
2009\end{array}$ & $\begin{array}{l}11 \# \\
227\end{array}$ & + & + & + & - & - \\
\hline $\begin{array}{l}\text { Dez } \\
2009\end{array}$ & $\begin{array}{l}12 \# \\
228\end{array}$ & + & + & + & - & - \\
\hline $\begin{array}{l}\text { Mar } \\
2010\end{array}$ & $\begin{array}{l}13 \# \\
230\end{array}$ & + & + & + & - & - \\
\hline $\begin{array}{l}\text { Abr } \\
2010\end{array}$ & $\begin{array}{l}14 \# \\
231\end{array}$ & + & & - & - & - \\
\hline $\begin{array}{l}\text { Mai } \\
2010\end{array}$ & $\begin{array}{l}15 \# \\
232\end{array}$ & - & + & + & - & + \\
\hline$\%$ & & 73,3 & $93 \% 3$ & $60 \%$ & $33 \% 3$ & $53 \% 3$ \\
\hline
\end{tabular}

Fonte: A própria autora.

Os atenuadores são palavras ou expressões que têm como objetivo diminuir o comprometimento do autor com os enunciados, marcando probabilidade ou incerteza. Nas reportagens, esses marcadores tendem a diminuir o comprometimento do jornalista em relação à ação do professor em sala de aula. Ou seja, a aplicabilidade das práticas sugeridas pela revista depende do desempenho do professor:

Exemplo 11

A revisão em processo e a final são passos fundamentais para conseguir de fato uma boa escrita. Nesse sentido, a maneira como você escreve e revisa no quadro-negro, por exemplo, pode colaborar para que a criança o tome como modelo e se familiarize com o procedimento. (NOVA ESCOLA, 2009, ed. 219, p. 45)

Os enfatizadores são bastante recorrentes nas reportagens didáticas, já que aparecem em 93,3\% das reportagens. Eles são responsáveis pela força ou pela certeza da mensagem (Exemplo 12). 


\section{Exemplo 12}

Antes de começar a atividade é preciso montar uma lista com os itens que serão analisados. (NOVA ESCOLA, 2009, ed. 220, p. 45)

Ao mesmo tempo que os autores enfatizam a sua certeza, estabelecem um vínculo afetivo com os seus leitores ao empregar os operadores atitudinais, já que esses são responsáveis pela expressão de surpresa, contentamento ou importância em relação à informação veiculada (Exemplos 13 e 14).

\section{Exemplo 13}

$\mathrm{Na}$ edição passada, esmiuçamos os preceitos teóricos do tema em nossa reportagem de capa. Agora, época em que o ano letivo engata de vez, discutimos uma prática importantíssima para o pontapé inicial ao trabalho: atividades de diagnóstico. (NOVA ESCOLA, 2009, ed. 220, p. 52)

\section{Exemplo 14}

Foi-se o tempo em que corrigir na escola significava apenas uma caça aos erros ortográficos e de pontuação nos textos dos alunos feita pelo professor. Ainda bem! Hoje, sabe-se da importância de desenvolver comportamentos escritores e processo de revisão se inclui aí. (NOVA ESCOLA, 2009, ed. 226, p. 90)

Acredito que os enfatizadores e os atitudinais nas reportagens analisadas podem ser vistos como complementares, visto que reforçam conjuntamente a intenção de mostrar que o jornalista compactua com o que está sendo exposto para o leitor.

Os marcadores denominados de automenção têm como finalidade proporcionar uma maneira de o escritor dirigir-se diretamente ao leitor ou, ainda, incluí-lo como um participante (HYLAND, 2000). Observei que não há a presença de marcadores da primeira pessoa do singular, entretanto, em cinco reportagens, o jornalista faz uso da primeira pessoa do plural (Exemplos 15 e 16). Isso pode ser interpretado como uma forma de o jornalista não se comprometer diretamente com o que está sendo popularizado. Quando o faz, inclui outros atores neste dizer, como o professor-leitor, o especialista/ consultor ou, ainda, toda a equipe da revista. 


\section{Exemplo 15}

Abaixo, listamos alguns dos principais pontos a ser observados e trabalhados nos textos da garotada. Também elencamos exemplos de como os contos podem ajudar a melhorá-los. (NOVA ESCOLA, 2009 , ed. 221, p. 55)

\section{Exemplo 16}

Um exemplo ajuda a esclarecer do que estamos falando. Vamos supor que a intenção seja propor um projeto sobre a vida dos dinossauros para alunos de $4^{\circ}$ ou $5^{\circ}$ ano. (NOVA ESCOLA, 2009, ed. 222, p. 79)

Em relação ao Exemplo 15, o uso do pronome nós, marcado desinencialmente, revela o posicionamento assimétrico discursivo assumido pela revista neste contexto, visto que esta pode ser vista como aquela que detém o conhecimento, que não mais recontextualiza, mas que lista e elenca o que deve ser ensinado, sem fazer referência a nenhum artigo ou livro específico que pudesse ter sido consultado. Já no Exemplo 16 há a presença de um "nós inclusivo", por meio do qual o jornalista convida o leitor a supor a elaboração de um projeto sobre dinossauros. Entretanto, a orientação diretiva permanece em outras reportagens no momento em que o jornalista prescreve ao leitor-professor, de acordo com o Exemplo 17.

\section{Exemplo 17}

É função do professor explicar que, embora os textos de autores profissionais não tenham traços do processo de produção, eles foram planejados, escritos, revisados diversas vezes e lidos por várias pessoas até estarem bons o suficiente para chegar às mãos do leitor. (NOVA ESCOLA, 2010, ed. 230, p. 67)

Nessa mesma perspectiva, os marcadores de atenção constituem um recurso linguístico importante na medida em que fazem um chamamento ao leitor, guiando a leitura e reforçando o que está sendo dito (Exemplo 18).

\section{Exemplo 18}

Lembre-se de que, em qualquer situação, a revisão fica mais proveitosa 
se um aspecto for ressaltado de cada vez. O excesso certamente confundirá a turma! (NOVA ESCOLA, 2009, ed. 226, p. 92)

Por fim, os marcadores metadiscursivos cumprem a função de dirigir o leitor ao posicionamento do jornalista diante de seu leitor. Diante disso, pode-se afirmar que as escolhas dos marcadores materializam o propósito comunicativo do gênero em questão.

\section{Considerações Finais}

A reportagem didática, neste contexto de análise, pode ser entendida como uma metáfora da escola, no momento em que materializa linguisticamente formas de identificar e representar o contexto escolar. Tais formas podem ser visualizadas nas escolhas dos marcadores metadiscursivos empregados, na configuração retórica e na configuração gráfica, conforme discutido nas subseções anteriores.

Por ser uma revista pedagógica destinada aos professores da educação básica, sua organização pode ser interpretada como uma apropriação da "realidade" escolar, materializada nas escolhas discursivas e textuais feitas pela Nova Escola. Para Fairclough (2008, p. 117), as ideologias são significações ou construções da realidade, contribuindo para a produção, reprodução ou transformação das relações de dominação. Nessa linha, o gênero reportagem didática apresenta um contexto ideológico em que o professor, em certa medida, reproduz o conhecimento, e a revista guia a prática docente por meio de atividades práticas que conduzem ao "sucesso", em termos de ensino e de aprendizagem. Tais práticas, a social e a discursiva, materializamse no texto por meio de pistas linguísticas, conforme foi possível analisar nas seções anteriores.

\section{Referências}

ANJOS-SANTOS, L. M.; LANFERDINI, P. A. F.; CRISTOVÃO, V. L. L. Dos saberes para ensinar aos saberes didatizados: uma análise da 
concepção de sequência didática segundo o ISD e sua reconcepção na revista Nova Escola. Linguagem em (Dis)curso, Tubarão, v. 11, n. 2, p. 377-400, 2011. Disponível em: <http://bit.do/bGPno>. Acesso em: 15 dez. 2011.

BAZERMAN, C. Gênero, agência e escrita. Tradução Judith Chambliss Hoffnagel. São Paulo: Cortez, 2006.

BAZERMAN, C. Gêneros textuais, tipificação e interação. Tradução de Judith Chambliss Hoffnagel. Organizado por Ângela Paiva Dionísio e Judith Chambliss Hoffnagel. São Paulo: Cortez, 2009.

BONINI, A. The distinction between news and reportage in the Brazilian journalistic context: a matter of degree. In: BAZERMAN, C.; FIGUEIREDO, D.; BONINI, A. (Orgs.). Genre in a changing world. Fort Collins, Colorado: The WAC Clearinghouse and Parlor Press, 2009. p. 196-222.

CARVALHO, G. Gênero como ação social em Miller e Bazerman: o conceito, uma sugestão metodológica e um exemplo de aplicação. In: MEURER, J. L.; BONINI, A.; MOTA-ROTH, D. (Orgs.) Gêneros: teorias, métodos, debates. 2. ed. São Paulo: Parábola, 2005. p. 130-149.

FAIRCLOUGH, N. Discurso e mudança social. Tradução Izabel Magalhães. Brasília: Ed. UnB, 2008.

HYLAND, K. Disciplinary discourses: social interactions in academic writing. Harlow: Pearson Education Limited, 2000.

HYLAND, K. Metadiscourse: exploring interaction in writing. London: Continuun, 2005.

MILLER, C. R. Genre as social action. Quarterly Journal of Speech, v. 70, n. 2, p. 151-167, 1984.

MOREIRA, T.; MOTTA-ROTH, D. Popularização da ciência: uma visão panorâmica do Diário de Santa Maria. In: CÍRCULO DE ESTUDOS LINGUÍSTICOS DO SUL - CELSUL, 8., 2008, Porto Alegre. Anais... Porto Alegre: Universidade Federal do Rio Grande do Sul, 2008. 
MOTTA-ROTH, D. Rhetorical features and disciplinary cultures: A genre-based study of academic book reviews in linguistics, chemistry and economics. 1995. Tese (Doutorado em Letras) - Universidade de Santa Catarina, Florianópolis.

MOTTA-ROTH, D. A construção social do gênero resenha acadêmica. In: MEURER, J. L.; MOTTA-ROTH, D. Gêneros textuais. Bauru; São Paulo: EDUSP, 2002. p. 77-109.

MOT'TA-ROTH, D. Análise crítica de gêneros: contribuições para o ensino e pesquisa de linguagem. D.E.LT.A., São Paulo, v. 24, n. 2, 2008. Disponível em: < http://bit.do/bGPnB>. Acesso em: 20 maio 2010. MOTTA-ROTH, D.; LOVATO, C. dos S. Organização retórica do gênero notícia de popularização da ciência: um desafio comparativo entre Português e inglês. Linguagem em (Dis)curso, Tubarão, v. 9, n. 2, p. 233-271, 2009.

OLIVERIRA, F. M. Análise de gênero da seção de metodologia em artigos acadêmicos eletrônicos de lingüística aplicada. 2003. Dissertação (Mestrado em Letras) - Universidade Federal de Santa Maria, Santa Maria.

SILVA, J.; FEITOSA, L. S. Revista Nova Escola: legitimação de políticas educacionais e representação docente. Revista HISTEDBR on-line, Campinas, n. 31, p. 183-198, 2008. Disponível em: < http://bit.do/ bGPnW>. Acesso em: 20 ago. 2010.

SWALES, J. M. Genre analysis: English in academic and research settings. New York; Cambridge: Cambridge University Press, 1990.

SWALES, J. M. Other floors, other voices: a textography of a small university building. Mahwah, NJ: Lawrence Erlbaum, 1998.

UNESCO. Professores do Brasil: impasses e desafios. Brasília, set. 2009. Disponível em: <http://bit.do/bGPn2>. Acesso em: 20 maio 2010. 